\title{
Deficiência e BPC: o que muda na vida das pessoas atendidas?
}

\author{
Deficiency and BPC: what changes in the lives of people assisted?
}

Wederson Rufino dos Santos ${ }^{1}$

${ }^{1}$ Instituto deBioética, Direitos Humanose Gênero. Caixa Postal 8011. 70673-970 Brasília DF. w.santos@anis.org.br
Abstract The aim of this article is to analyze the impact of well-being provoked in the life of the disabled people after the Cash Benefit to Disabled People (BPC). The BPC is a social assistance benefit consisting in an unconditional and monthly transference of the equivalent of a minimum wage, to poor peoplewith deficiency and elders with more than 65 years. The methodology used was a case study with qualitativeand quantitativetechniques of data collection and analysis. BPC performed interviews guided by a semi-structuralized questionnaire with 30 people with deficiency. The re sults showed that: (1) BPC is an important mechanism of security of incomein the consumption of basic goods of feeding, health treatments and expenses with housing of deficient and its families; (2) disabled people had related the concession of the benefit to the increase of social and financial independence in relation to their families, contributing to expand theidea of autonomy and citizenship; (3) it is an instrument capable of protecting the ben efited ones and their families of the situation of social vulnerability result of the poverty, although the mothers of the deficient children leave the work market to take care of their children and do not receive any kind of social protection from the State.

Key words Disability, Continuous cash benefit programme, Impact of well-being, Social protection
Resumo Esteartigo tem como objetivo analisar o impacto de bem-estar provocado na vida das pessoas deficientes apóso acesso ao Ben efício dePrestação Continuada (BPC). 0 BPC éum benefício da assistência social e consistena transferência incondicional emensal de renda, equivalentea um salário mínimo, destinado também às pessoas pobres idosas acima de 65 anos. A metodologia do estudo teve técnicas qualitativas e quantitativas de coleta e análise de dados. Foram realizadas entrevistas orientadas por um questionário semi-estruturado com trinta pessoas com deficiência atendidas pelo BPC. Os principais resultados. Os principais resultados da pesquisa mostraram que: (1) o BPC se configura como mecanismo de segurança de renda, proporcionando consumo de bens básicos de alimentação, tratamentos de saúde e gastos com moradia dos deficientes e suas famílias; (2) as pessoas deficientes relacionaram a concessão do benefício com 0 aumento da independência social e financeira delasem relação assuasfamílias, contribuindo para a ampliação das noções de autonomia ecidadania; (3) o BPC é um instrumento capaz de proteger os beneficiados e suas famílias da situação de vulnerabilidadesocial resultanteda pobreza ou desemprego, muito embora as mães das crianças deficientes saiam do mercado de trabal ho para exercer o cuidado diário dos filhos enão recebam nenhum tipo de proteção social por parte do Estado.

Palavras-chave D eficiência, BPC, Impacto de bem-estar, Proteção social 


\section{Introdução}

Duranteum longo período, a deficiência foi compreendida apenas como disfunção biológica, como tragédia de responsabilidade individual, sendo subjugada ao confinamento ou aos cuidados familiares ${ }^{1}$. Somente a partir da década de setenta, com o fortalecimento do marco dos direitos humanos e da politização dos movimentos sociais de pessoas deficientes, a rei vindicação por proteção social dos direitos de cidadania dessa parcela da população começou a redirecionar o ordenamento político e jurídico, passando a ser tema na área da justiça social ${ }^{1}$ (há um intenso debate na literatura nacional einternacional sobre como devem ser apresentadas as nomenclaturas relativas às pessoas que vivem a experiência da deficiência. Por considerar esse debate extremamenteimportante, mas não nesse momento, durante todo este artigo foram usados de forma indiscriminada os termos pessoa com deficiência, deficiente, pessoa deficiente e pessoa portadora de deficiência para representar todo 0 conjunto das pessoas que sofrem opressão pelo corpo devido à experiência da deficiência).

Em poucos anos, tratados internacionais e pressões políticas de movimentos sociais e do meio acadêmico foram responsáveis pela redescrição da deficiência como um tema na esfera da justiça e da democracia, e não somente na esfera biomédica². Assim, o atual campo de estudos internacionais sobrea deficiência tem aproximado o tema cada vez mais das ciências sociais, 0 que tem favorecido a compreensão do corpo deficiente como uma expressão da diversidade humana. N essa perspectiva, as reivindicações sobre a deficiência passaram a ser também de ajustes sociais, estruturais e políticos para tratar o tema com mais igualdade. Pois reconhecer a experiência da deficiência como uma expressão da diversidade é valorizar a diferença entre as pessoas e assumir o compromisso democrático de garantir a igual dade ea liberdade nas sociedades a partir do reconhecimento dessas diferenças.

Essa aproximação da deficiência do campo das ciências sociais proporcionou um questionamento contundente sobre como, até então, as ciências biomédicas compreendiam a deficiência e ofereciam recursos explicativos sobre ela. Aos poucos, a narrativa das ciências sociais sobre a deficiência fragilizou o predomínio dos saberes biomédicos, o que favoreceu a ampliação do escopo de reivindicações sobre a deficiência ${ }^{3}$. Uma dessas reivindicações diz respeito à necessidade de políticas sociais para as pessoas deficientes, tendo como objetivo a garantia da cidadania, da proteção social e da inclusão social dessa população na sociedade.

Por quecuidar das pessoas deficientes ou protegêlas socialmente? Essa éuma das questões centrais no campo dos estudos sobre deficiência ${ }^{3,4}$. Proteger socialmente as pessoas deficientes significa a responsabilidade do Estado democrático em atender uma demanda específica para promover justiça e não meramente uma medida paternalista ou benevolente. A guinada teórica que permitiu desvendar a deficiência não mais restrita à esfera individual e patológica, passando a ser uma questão social pautada na responsabilidade do Estado em promover justiça social, lançou luz sobre o debate dos direitos humanos das pessoas portadoras de deficiência. E, consequentemente, transferiu a atribuição do cuidado e proteção do campo da benevolência ou atribuições familiares para o campo da garantia de direitos fundamentais, amparada em princípios éticos ena solidariedade como uma questão pública.

Por essa perspectiva, a diversidade humana não simplesmente é parte constituinte de qualquer sociedade, como também a depender de como as sociedades se organizam, algumas expressões da diversidade podem resultar em fenômenos de desigualdade ${ }^{5}$. Se pouco sensível éo modo pelo qual a sociedade se organiza para receber a diversidade corporal, a compreensão da deficiência como manifestação da diversidade humana pode transformar-se em uma experiência de discriminação, exclusão social e opressão pelo corpo ${ }^{3,6}$. Sendo assim, em sociedades com valores democráticos, dispor demecanismosinstitucionais para proteger as diversidades implica em definir quais diversidades devem ser protegidas e como protegêlas.

O Benefício de Prestação Continuada (BPC) éuma política pública de combateàs desigualdades das mais importantes no país para as pessoas pobres deficientes ${ }^{7}$. O BPC é um benefício da assistência social garantido na Constituição $\mathrm{Fe}$ deral de 1988, regulamentado pela Lei $n^{\circ} 8.742$, de 7 de dezembro de 1993 (Lei Orgânica da Assistência Social - LOAS) eimplantado de forma efetiva em 2 dejaneiro de 1996. O BPC éuma transferência incondicional derenda, equivalentea um salário mínimo, destinado às pessoas pobres com deficiência e também às idosas acima de 65 anos ${ }^{8,9}$. Em dezembro de 2007, o benefício assistencial atendia mais de 2,5 milhões de pessoas, sendo que, desse total, mais de 1,4 milhões são pessoas com deficiência e quase 1,2 milhões são idosos acima de 65 anos $^{10}$. 
Para requerer o BPC, a pessoa idosa ou portadora de deficiência deve procurar um dos postos do Instituto Nacional deSeguro Social (INSS), preencher o formulário de solicitação do benefício e de declaração de renda dos membros da família, que não pode ultrapassar $1 / 4$ de renda familiar per capita, comprovar residência eapresentar documentos próprios e da família para avaliar os critérios derenda ${ }^{10}$. A pessoa deficiente será encaminhada para uma avaliação médicopericial, em que os médicos peritos do INSS verificam, entre outras coisas, a aptidão para a atividadelaboral, níveis de dificuldades visuais, auditivas, de locomoção e fala. A pessoa beneficiada passa por uma revisão a cada dois anos e, nessa revisão, a situação social e níveis de vulnerabilidade são também avaliados por meio da avaliação social evisita domiciliar ${ }^{10}$.

Este artigo é resultado de uma pesquisa intitulada "D eficiência em questão: análise de impacto do BPC", do Programa Institucional de Bolsas deIniciação Científica (PIBIC) da Universidade de Brasília (UnB), concluída em 2007. A pesquisa que fundamentou este artigo tevecomo objetivo analisar o impacto de bem-estar provocado na vida de deficientes após a concessão do BPC. Conhecer os impactos do BPC na vida dos deficientes é essencial para a avaliação, monitoramento e aperfeiçoamento desse benefício da assistência social.

\section{Métodos}

A pesquisa que fundamentou esteartigo foi baseada em um estudo de caso, com uso de técnicas qualitativas e também quantitativas de levantamento e análise de dados ${ }^{11}$. A metodologia consistiu em sete etapas distintas: (1) levantamento sobre a legislação do BPC, levantamento bibliográfico sobre teorias de deficiência e proteção social; (2) trabalho decampo - levantamento eanálise de todos os processos de pedido do BPC para pessoas com deficiência no período de janeiro de 2004 a janeiro de 2006 da agência do IN SS da cidade de U naí (M G); (3) levantamento na página eletrônica do M inistério do Desenvolvimento Social e Combate à Fome (MDS) de quantos, do total de processos analisados na fase anterior, re sultaram em benefícios concedidos e quantos re sultaram em benefícios negados; (4) elaboração do instrumento de coleta de dados, que resultou em um questionário aberto semiestruturado a ser aplicado a $20 \%$ do total de pessoas com deficiência beneficiadas pelo BPC no período citado ante- riormente; (5) aplicação do pré-testedos questionários a 10\% da amostra para verificar a eficácia do instrumento e realizar possíveis adequações; (6) aplicação das entrevistas, que foram realizadas mediante gravação de voz, a trinta pessoas com deficiência beneficiadas pelo BPC, o quecorrespondea $20 \%$ das pessoas deficientes beneficiadas pelo BPC no período de 2004 e 2005 na cidade de Unaí (MG); (7) transcrição das entrevistas, análise qualitativa em profundidade dos dados levantados e comparação com as hipóteses do projeto por meio de técnicas qualitativas de codificação dos dados e de teoria fundamentada ${ }^{12}$.

A escolha pela cidade de Unaí (MG) para a realização da pesquisa de campo sejustificou pela possibilidade de realizar um estudo de caso em profundidade, pois: (1) a cidade possui apenas uma agência do INSS e essa mesma agência permitiu 0 acesso a todos os processos do BPC para pessoas com deficiência real izados no período de janeiro de 2004 a janeiro de 2006, o que torna os resultados da pesquisa confiáveis e representativos. Em maio de 2007, 1.023 deficientes eram beneficiados pelo BPC em Unaí (MG) e, desse total, foram concedidos 154 ben efícios no período de janeiro de 2004 a janeiro de 2006, o que representa $15 \%$ do total de ben eficiados na cidade. Portanto, a amostra para a aplicação das entrevistas foi composta por uma escol ha aleatória de $20 \%$ do total dos 154 beneficiados nos anos de2004 e2005; (2) a concentração em umaúnica agência do INSS de todos os processos que foram analisados permitiu uma identificação de todos os sujeitos envolvidos diretamente tanto na concessão do BPC quanto das pessoas com deficiência beneficiadas; ( 3 ) o portedemográfico da cidade (pouco menos de 80 mil habitantes) e a localização próxima ao Distrito Federal (pouco mais de 140 quilômetros) permitiram uma pesquisa de campo com facilidade, agilidadee qualidade; (4) todos esses pontos levantados anteriormentepermitem a realização de possíveis estudos futuros para levar adiante os achados da pesquisa que fundamentou este artigo.

A pesquisa não ofereceu risco moral, físico ou material aos entrevistados, além dos existentes nas relações sociais cotidianas, uma vez que: (1) o sigilo das informações de todos os participantes será garantido; (2) só participaram da entrevista aqueles que compreenderam os procedimentos e objetivos da pesquisa como pesquisa acadêmica parafins de conhecimento científico e que consentiram com a gravação da entrevista por meio de gravador de voz; (3) das pessoas com deficiência que recebem o BPC, fo- 
ram entrevistadas somente aquelas que já recebem o benefício há pelo menos seis meses, permitindo que os entrevistados tenham uma avaliação sobre as mudanças provocadas pelo recebimento do benefício; (4) todos os participantes da pesquisa tomaram conhecimento antecipado de que a participação é voluntária, sem remuneração e que poderiam desistir de participar da entrevista a qualquer momento, mesmo depois de iniciada ou finalizada a gravação; (5) as pessoas com deficiência que recebem o BPC foram informadas de que 0 acesso ao nome e endereço delas só foi permitido pela agência do IN SS para fins exclusivos dessa pesqui sa e que a pesquisa só teve prosseguimento somente após a autorização das pessoas atendidas pelo BPC.

Durante um mês, foram entrevistadas trinta pessoas com deficiência beneficiadas pelo BPC na cidade de Unaí (MG), o que representa $20 \%$ do total de benefícios concedidos no período de janeiro de 2004 a janeiro de 2006 na cidade. Durante esse período, ocorreram 430 pedidos de acesso ao BPC por pessoas deficientes na única agência do INSS da cidade. Desses 430 processos de pedido de concessão, houve 276 pedidos negados (64\%) e 154 ben efícios concedidos (36\%). A amostra de deficientes beneficiados entrevistados para a pesquisa foi composta por uma escoIha al eatória dos ben eficiados a partir desse percentual de $36 \%$, por meio do conhecimento dos dados demográficos que os identificassem (nome, data do pedido, endereço eidade).

\section{Resultados ediscussão}

Três achados foram centrais à análise de dados na pesquisa. Os resultados encontrados mostraram que: (1) o BPC se configura como mecanismo de segurança de renda e garante 0 consumo de bens básicos de alimentação, tratamentos de saúdee gastos com moradia dos deficientes esuas famílias; (2) as pessoas deficientes relacionaram a concessão do benefício com o aumento da independência social e financeira delas em relação as suas famílias, contribuindo para a ampliação das noções de autonomia e cidadania; (3) o BPC é um instrumento capaz de proteger os beneficiados e suas famílias da situação de vulnerabilidade social resultante da pobreza, desemprego e emprego informal, muito embora as mães das crianças deficientes saiam do mercado de trabaIho para exercer o cuidado diário dos filhos e não recebam nenhum tipo de proteção social por parte do Estado.
As Tabelas 1, 2 e 3 mostram o perfil das pessoas atendidas peloBPC entrevistadas. A Tabela 1 demonstra os tipos de deficiência, doenças e impedimentos corporais das pessoas.

As diversas deficiências recuperadas na pesquisa compõem um cenário representativo dos tipos de restrições de habilidades experimentadas por pessoas que vivem em contato com ambientes hostis às diversidades corporais. Ao lado de um grande número de deficiências físicas e mentais, na amostra, apareceram também vários tipos de doenças, como câncer, aids e diabetes. A recuperação pela pesquisa dessas doenças atendidas pelo benefício indica um alargamento nos últimos anos do conceito de deficiênciautilizado para fins de concessões do BPC ${ }^{13-15}$.

Das entrevistadas, vinte pessoas declararam necessitar de cuidados médicos constantes, dentre entre eles consultas médicas periódicas, uso de remédios diários, fisioterapias e alimentação balanceada. Do total da amostra, dez delas necessitam decuidados especiais eatenção 24 horas por dia de um cuidador. E, do total das pessoas entrevistadas, nove pessoas deficientes combinam necessidade de cuidados médicos constantes com necessidade de cuidados especiais diários. E ainda, doze pessoas beneficiadas declararam que a situação de pobreza, que persiste mesmo depois da concessão do BPC, faz com que a experiência da deficiência seja agravada por que a renda do beneficiado e da família não permite a continuidade de tratamentos de saúde constantes e gastos com todos os remédios necessários. A Tabela 2 discrimina a idade das pessoas entrevistadas.

Em todo o país, crianças e adolescentes são a faixa etária de maior incidência de pessoas deficientes atendidas pelo BPC: um em cada cinco BPCs concedidos no país é para crianças e ado-

\begin{tabular}{lc}
\hline \multicolumn{1}{c}{ Tabela 1. Tipos de deficiências/doenças. } \\
\hline \multicolumn{1}{c}{ Deficiências/doenças } & Pessoas \\
\hline Deficiências físicas e motoras & 9 \\
Deficiências mentais & 8 \\
Doenças crônicas & 9 \\
Sequelas de acidente vascular cerebral (AVC) & 2 \\
Doenças genéticas & 2 \\
Total & 30
\end{tabular}

Fonte: Pesquisa“ “D eficiência em questão: uma análise deimpacto do BPC", financiada pelo CN Pq. Realizada duranteos anos de 2006 e 2007 em Unaí (M G). 
lescentes até dezoito anos de idade ${ }^{10,16}$. As de mais idades encontradas na pesquisa indicam a concessão do BPC para deficientes em diferentes idades, mas que têm em comum o fato de ainda estarem em idade considerada produtiva.

A assistência social percorreu uma longa trajetória até se transformar em uma política pública com status de direito social expresso constitucionalmente ${ }^{17}$. A pós a expressão na Constituição Federal de 1988, o fortalecimento da idéia da assistência social como política pública ocorreu de maneira lenta ao longo dos anos noventa e 2000, quando o Estado passou a fazer uso mais fortemente de políticas sociais detransferência derenda e de proteção social como combate à pobreza e à desigual dade social'. Por envolver um grande volume de recursos públicos em temas centrais como éa pobreza egarantia de direitos humanos, o acompanhamento e avaliação das políticas sociais sempre é alvo de debates importantes em uma sociedade democrática. Com o BPC não é diferente, muito embora haja uma ausência no país de estudos e pesquisas sobre o impacto do BPC na vida das pessoas deficientes atendidas.

A deficiência é um tema desafiante para as políticas públicas por estar articulada com mercado de trabalho restritivo e fragilidade das políticas sociais para a garantia de cidadania dessa parcela da população. Além das demandas por medidas no mercado de trabal ho para promover inclusão social, a deficiência éum tema alarmante quando articulada à pobreza. Para ilustrar esse cenário, um levantamento feito por $M$ arcelo N eri mostrou que, do total das pessoas com deficiência no país, $29,05 \%$ delas vivem em situação de miséria, ou seja, vivem em famílias com rendaper capita abaixo de meio salário mínimo ${ }^{18}$. Esse número que combina deficiência e pobreza é ainda mais preocupante quando observadas as que 0

Tabela 2. Idade.

\begin{tabular}{lc}
\hline \multicolumn{1}{c}{ Faixa etária } & Pessoas \\
\hline Até 18 anos & 8 \\
Entre 19 e 30 anos & 4 \\
Entre 30 e 40 anos & 9 \\
Entre 40 e 60 anos & 9 \\
Total & 30 \\
\hline
\end{tabular}

Fonte: Pesquisa “D eficiência em questão: uma análise de impacto do BPC", financiada pelo CN Pq, realizada durante os anos de 2006 e 2007 em U naí (M G). autor denomina de pessoas com percepções de incapacidade (PPI), aquelas que autor denomina de deficiências graves, que representam 2,5\% das pessoas deficientes no país. D essetotal de mais de 4,2 milhões de pessoas com deficiências graves no Brasil, o número de pessoas vivendo na miséria aumenta para $41,62 \%{ }^{18}$.

Segundo N eri, a categoria pessoas perceptoras de incapacidade (PPI) é uma categoria que se refere às pessoas com deficiências graves, sobretudo aquelas que não participam dos espaços sociais da vida cotidiana devido às restrições de movimentos e habilidades ${ }^{18}$. Essa categoria é para sediferir da categoria pessoas com deficiência, que éutilizada para se referir ao corpo com lesão leve que, ao participar dos espaços sociais, entra em contato com um ambiente que não prevê e não está adequado à diversidade corporal. No entanto, essa classificação do autor vai deencontro com um movimento internacional no marco dos direitos humanos de compreensão da deficiência como opressão social. Pois, o modelo social da deficiência - uma correntepolítica eteórica nascida no Reino Unido nos anos setenta - redescreveu o modo pelo qual a deficiência antes era compreendida apenas como desvantagem biológica ${ }^{1,6}$.

Portanto, a categoria PPI aproxima muito a deficiência do modelo biomédico, o que dificulta a negociação da deficiência como uma restrição social, matéria de justiça social. A pesar dessa ressalva, os números levantados por N eri são importantes para problematizar a necessidade de política de assistência social e proteção social, uma vez que há ocorrência de incapacidade para o trabaIho, ou mercado de trabal ho pouco inclusivo, aliado à pobreza absoluta que resulta em situações de extrema vulnerabilidade social dos deficientes.

Há pessoas com deficiência para as quais as políticas de inclusão são insuficientes para promover a entrada no mercado de trabalho,seja pelo grau de restrição corporal, seja pela idade ou pouca formação educacional e profissional. Para estes casos,o BPC foi criado como uma política social com o objetivo deatender os direitos de cidadania das pessoas pobres com deficiência que necessitam de assistência social ${ }^{6}$. Das pessoas deficientes entrevistadas, todas reportaram melhoria significativa em suas condições de vida após o recebimento do BPC. Segue o trecho de um dos entrevistados: Esse benefício é muito bom porque meajuda com as coisas que eu preciso mais, remédios e até comida. Porque eu sou sozinho e não consigo mais trabalhar por causa do problema na perna. M as o bom mesmo era quando eu trabalhava! Acho que todo mundo acha melhor 
trabalhar, ter o seu dinheiro do trabalho. E também eu ganhava mais do que só o salário do benefício. Mas eu não posso trabalhar mais, então, 0 benefício é muito bom. (Entrevistado de 45 anos, com deficiência física)

Além disso, esse relato demonstra a centralidade que 0 trabalho mantém em nosso ordenamento social. No entanto, a experiên cia da deficiência provoca a necessidade de um realinhamento do que seja o papel do Estado em fazer justiça a essa população, fazendo uso de uma política pública de transferência de renda como medida de reparação de desigualdades.

O BPC possui critérios de acesso bastante seletivos, o que faz com que o benefício seja direcionado a pessoas em extrema pobreza ${ }^{14}$. 0 critério de renda per capita utilizado também faz com que não só a situação financeira do deficiente requerente do benefício seja avaliada para a concessão acontecer, mas também de toda a sua família. Essa exigência da pobreza familiar para a concessão do BPC ao deficiente torna os rendimentos do benefício como deuso prioritário para alimentação, tratamentos de saúde e gastos de moradia do deficiente e sua família, como mostra a Tabela 3.

As perguntas permitiam que as pessoas escoIhessem mais de um item. Como exemplo de que os rendimentos do BPC resultam em melhorias de bem-estar, pois são utilizados com despesas básicas de al imentação e tratamentos médicos, têm-se o seguinte trecho de uma das entrevistadas: Eu fui atrás de tentar receber o benefício pra minha filha porquea renda aqui de casa não dava para todas as despesas dela. Tem as fraldas, que ela usa fraldas o tempo todo. 0 sremédios que são muito caros. 0 tratamento dela em Braślia, que as despesas de passagem a gentenão tem porquea gentevai no ônibus da prefeitura pra lá. M as a gente já tem os gastos com

Tabela 3. Cesta de consumo do BPC.

\begin{tabular}{llr}
\hline \multicolumn{1}{c}{ Consumo } & Frequência & Pessoas \\
\hline Alimentação & Prioridade & 30 \\
Tratamentos médicos & Prioridade & 22 \\
Tarifas de água, luz e aluguel & Prioridade & 16 \\
Lazer & Casualmente & 2 \\
Investimentos & Casualmente & 0 \\
\hline
\end{tabular}

Fonte: Pesquisa “D eficiência em questão: uma análise de impacto do BPC", financiada pelo CN Pq, realizada durante os anos de 2006 e 2007 em Unaí (M G). alimentação aqui! E, por isso, eu fui atrás para ela poder ter uma vida melhor! ( $M$ ãedeuma criança de cinco anos com deficiência mental)

Ainda, apenas três pessoas beneficiadas re portaram o uso do benefício com transporte e apenas duas pessoas relataram o uso do benefício com algum tipo de lazer. E nenhum entrevistado relatou o uso dos rendimentos do benefício com al gum tipo de atividade para geração derenda ou investimentos. Sendo assim, a renda do BPC éimportante como proteção social egarantia das necessidades básicas, não promovendo aumento nos padrões de consumo de bens se cundários, lazer ou geração de renda.

Além da constatação de que o ben efício consiste, principal mente, em atender as necessidades mínimas de sobrevivência dos beneficiados, a importância do benefício como proteção social se revela também quando se constata o papel desempenhando pelo BPC na composição dos rendimentos da família dos deficientes. Das pessoas entrevistadas que recebem o BPC, treze pessoas têm o benefício como a única renda da família e dezessete têm o BPC como a principal renda familiar. A pesar de se ter dezessete pessoas que não têm o BPC como a única renda familiar, em doze desses casos os rendimentos das famílias não ultrapassam dois salários mínimos. E essa renda familiar complementar ao BPC nos dezessete casos, em treze deles essa ren da complementar écomposta por rendimentos oriundos detrabalho informal. 0 caráter restritivo do benefício que diz respeito tanto ao critério de renda per capita da família para a elegibilidade, quanto o valor do benefício de um salário mínimo, explicam a persistência da situação de vulnerabilidadesocial das pessoas deficientes beneficiadas pelo BPC, mesmo depois do recebimento do benefício há mais de seis meses.

A melhoria das condições de bem-estar dos deficientes após o recebi mento do BPC está para além do aumento e da garantia de segurança da renda familiar. As pessoas entrevistadas relacionaram o recebimento do benefício com o aumento da sua autonomia e independência social em relação às famílias. Antes, a necessidade dos cuidados familiares e a dependência financeira total da família faziam com que as pessoas deficientes tivessem uma autonomia diminuída, o que contribuía para a situação de frustração frente à dinâmica familiar e à sociedade. Como exemplos, têm-se o seguinte relato de um dos entrevistados que revelou a importância do BPC para a ampliação da autonomia e independência do beneficiado: Foi muito bom meu irmão receber 0 
benefício porque ele não consegue trabalhar por causa do problema decabeça eeletinha muita vontade de ter o dinheiro dele, agora ele tem e não precisa depender de ninguém. Isso éo que eu acho que foi mais importante: ele tinha até depressão, ele era meio revoltado por que queria trabalhar e não dava conta, e precisava depender dos outros, da mamãe, nós irmãos deles que ajudavam. M as quando ele passou a receber o dinheiro dele, ele passou a se sentir bem melhor. (Entrevistada 5, irmã de uma pessoa com deficiência mental resultante de complicações no parto)

Foram treze relatos de pessoas adultas acima de dezenoveanos que relacionaram o recebimento do BPC com o aumento da independência e noções de autonomia. É significativo essenúmero de pessoas adultas acima de dezenove anos de idade relatar melhoria da autonomia e independência devido o recebimento do BPC, já que do total dos trinta entrevistados, havia 22 pessoas acima de dezenove anos.

O BPC, portanto, tem um repasse de valor ainda restritivo, se levada em consideração que as pessoas atendidas pelo benefício combinam pobreza extrema com gastos constantes em tratamentos de saúde e alimentação. Entretanto, 0 benefício se configura como uma importante política social para atender os mínimos sociais das pessoas deficientes e promover a melhoria das noções de autonomia, independência e cidadania das pessoas deficientes atendidas.

O BPC é um benefício da assistência social que possui mais de dez anos de implementação e é o maior programa de transferência direta de renda, em volume de recursos envolvidos, do país. Ele é menor apenas do que o Programa Bolsa-Família (PBF), em número de pessoas atendidas, já que em dezembro de 2007 o BPC atendia mais de 2,5 milhões de pessoas, enquanto 0 Bolsa-Família atendia mais de 11 milhões de famílias ${ }^{10}$. O BPC é um direito social previsto no artigo 203 da Constituição de 1988 e começou a ser implementado em janeiro de 1996. Muito embora seja um benefício da assistência social, portanto, financiado pelo Fundo $\mathrm{N}$ acional de Assistência Social (FNAS), e a gestão seja de responsabilidadedo M DS por intermédio da Secretaria Nacional de Assistência Social (SNAS), a implementação eoperacionalização do benefício estáa cargo das agências do INSS detodo o paí $5^{10}$.

Segundo Amartya Sen, a eficácia no combate à pobrezaeà desigualdade socioeconômica depende da compreensão da pobreza não somente como baixo nível de renda, mas como privação de capacidades básicas ${ }^{19}$. Ou seja, a privação de renda se configura em situação de desvantagem social em sentido absoluto, mas determinadas desvantagens como a idade, doenças ou certas deficiências reduzem o potencial de um indivíduo transformar renda em capacidades para alcançar uma vida que ele considera com valor ${ }^{19,20}$. Para Sen, as políticas públicas são mecanismos para responder às demandas sociais, amparados em princípios éticose dejustiça social, etêm, nesse sentido, função fundamental para beneficiar os indivíduos que têm o potencial reduzido para transformar suas capacidades em funcionalidades ${ }^{20}$.

Dos trinta entrevistados, quinze beneficiados relataram aumento da segurança social, ou seja, o BPC éresponsável pela proteção social de renda das pessoas com deficiência que antes dependiam da ajuda familiar ou da caridade de vizinhos ou comunidades religiosas. Como exemplos, segue o trecho deum relato de um ben eficiado em queo BPC écompreendido como uma política pública que responde às demandas sociais por meio da proteção social sob a responsabilidade do Estado: Antes de receber o benefício, eu recebia ajuda era do meu filho quenão mora aqui comigo, queele écasado, já tem família, era elequemeajudava. Era elequenão deixava faltar as coisasquea gentemais precisa, que é comida e remédios. N em era sempre também, porque ele também tem a família dele e nem dá pra ficar assim ajudando a gente o tempo todo porqueeletambém épobre. (Entrevistado com deficiência física, 40 anos)

O BPC, nesse sentido, apesar de se configurar como um benefício com critérios deelegibilidade erepasse de valores seletivos, integra uma redede proteção social baseada em políticas públicas em que o Estado é responsável por atender as demandas sociais, promovendo a garantia da cidadania das pessoas com deficiência pobres no país.

Outro impacto de segurança social importante que o BPC provoca na vida das pessoas deficientes diz respeito à proteção contra as vulnerabilidades provocadas pela informalidade no mercado de trabal ho. O BPC não passa a incentivar a informalidade dos beneficiados, nem dos familiares, para manterem os critérios queconfiguram o direito ao benefício - tanto de renda quanto de incapacidade para o trabal ho. Na verdade, o que pode ser verificado é que o BPC se configura em segurança social eeconômica, uma vez que as pessoas beneficiadas ou seus familiares já estavam submetidos à situação de informalidade no mercado de trabalho antes do recebimento do benefício.

Portanto, a persistência da informalidade se explica não pelo recebimento do BPC e pelas es- 
tratégias deinserção no mercado informal detrabalho para a manutenção do recebimento, mas pelas condições dos deficientes e suas famílias, tais como pobreza, baixa qualificação profissional e educacional ou desemprego. Houve relatos depessoas com experiências de informalidadeno mercado de trabalho - do próprio beneficiado ou dos mantenedores da família - antes e também depois do recebimento do BPC. 0 trecho abaixo é um exemplo: Não dou conta mesmo de trabalhar, porque sinto dor, porque nunca consegui nem terminar de estudar. Eu me virava e me viro ainda é fazendo artesanato em casa pra vender eajudar nas despesasaqui. Às vezes, eu já tentei fazer um curso de computação, essas coisas, mas nem isso eu consegui terminar de concluir porque eu faltava demais, por causa de passar mal sempre. Tem semana que fico quatro dias direto de cama. Então como é que estudo ou trabalho?! Os "bicos" que faço com artesanato ajudam porque só o dinheiro do artesanato não dá. (Entrevistada com 25 anos, com diabetes)

Ao contrário do que à primeira vista poderiam indicar, o BPC eseus critérios de elegibilidade não incentivam à informalidade, pelo contrário, com a garantia de uma renda mensal, o benefício protege de forma razoável as pessoas com deficiência esuas famílias da situação de vulnerabilidade social provocada pelas experiências de inserção no mercado de trabalho pela via informal.

O BPC e a informalidade no mercado de trabalho se relacionam ainda em outro aspecto. As desigual dades provocadas pela experiência da deficiência atingem também as mães dos deficientes, que têm de sair do mercado de trabalho para exercer as atividades exclusivas do cuidado diário, ou tentar conciliar atividades informais com o cuidado do filho. Dos BPCs concedidos para pessoas portadoras de deficiência em todo o país, mais de $20 \%$ são para crianças e adolescentes até dezoito anos de idade, ou seja, um BPC a cada cinco concedidos é para essa faixa etária ${ }^{10,16}$.

O grandenúmero de deficientes atendidospelo BPC com menos de dezenoveanos de idade revela a proteção social do benefício às crianças eadolescentes deficientes pobres; entretanto, expõe 0 problema das mães que saem do mercado de trabal ho para se dedicar ao cuidado integral dos fiIhos $^{16,21}$. Das trinta pessoas entrevistadas, havia oito crianças atendidas pelo BPC e ainda quatro adultos com deficiências graves, e nesse total de doze casos, mães ou outro familiar dedicam-se totalmente ao cuidado do deficiente- o queobriga esses cuidadores a não fazerem parte do mercado formal detrabalho. Como exemplo demães que saem do mercado de trabalho para exercer o cuidado do filho, tem-se o seguinte trecho deuma das entrevistadas: Depois que ele adoeceu, eu tive que parar de trabalhar e as coisas pioraram. $M$ as com o benefício é como se eu tivesse voltado a ser quando eu trabalhava. Porque as despesas dele ficam todas por conta do benefício. Eu já cuidava da minha mãe porque ela já era doente, mas depois do meu filho ter a doença, eu passei a cuidar dos dois. Eu nem posso sair eficar muito tempo fora, quando "faço" unhas, às vezes tenho de voltar correndo pra cuidar, por que quando não émeu filho queprecisa de mim, é minha mãe. ( $M$ ãe de um beneficiado pelo BPC de dez anos com leucemia)

0 problema dessa relação delicada entre 0 cuidado diário do deficiente e a informalidade no mercado de trabalho consiste justamente no fato de que não existe nenhum tipo de política pública de proteção às pessoas cuidadoras de deficientes.

Um dos critérios de elegibilidade para acesso ao $\mathrm{BPC}$ diz respeito à incapacidade para o trabaIho ${ }^{9}$. E esse critério é uma das grandes controvérsias para concessão do $B P C$, uma vez que determinar o que seja incapacidade para o trabaIho não é uma tarefa simples, o que acaba por restringir 0 acesso de pessoas deficientes ao direito social ${ }^{7,14}$. Além disso, determinadas deficiências não são total mente incapacitantes para o trabalho; no entanto, a experiência da deficiência ea restrição de habilidades resultante dela fazem com que as pessoas deficientes tenham desvantagens no mercado de trabal ho por ele ser pouco adaptado às características dos deficientes, impedindo a promoção da autonomia e independência financeira e social dessas pessoas.

D as trinta pessoas entrevistadas, havia 22 adultos acima de dezenoveanos deidadee desses, oito beneficiados possuem deficiências total menteincapacitantes para o trabalho. D os demais catorze adultos beneficiados pelo BPC entrevistados, dez pessoas relataram que não são totalmente incapazes para o trabalho; entretanto, a deficiência experimentada por eles os impedia de participar do mercado de trabal ho com as mesmas condições que uma pessoa sem nenhum tipo de deficiência. Além disso, relataram também queo mercado de trabalho, por não estar preparado para incorporar a pessoa deficiente, discrimina e restringe direitos dessa parcela da população. Assim, apesar da controvérsia existente com relação aos critérios de el egibilidade serem pouco claros sobrea incapacidadepara o trabal ho, o BPC cumpre o seu papel de política pública de proteção social por atender as pessoas na situação de vul- 
nerabilidadesocial independenteda incapacidade total ou parcial para o trabalho.

Há, portanto, nas narrativas das pessoas deficientes atendidas pelo BPC, uma relação entrea efetivação do direito à assistência social e a possibilidade de mudança nas noções de cidadania experimentada por essas pessoas. 0 que possibilita essas narrativas são mudanças perceptíveis nas noções de bem-estar devido ao acesso ao benefício, pois o perfil do público-alvo do $B P C$, composto por pessoas muito pobres e muito vulneráveis socialmente, permite que a garantia mensal de um salário mínimo altere os padrões de consumo das famílias dos deficientes - mesmo que esse consumo seja de bens básicos como alimentação, tratamentos de saúde e despesas domésticas.

\section{Considerações finais}

O BPC se configura como política-chave de proteção social a idosos e pessoas deficientes pobres incapazes para o trabalho por fazer uso de um mecanismo de reparação de desigualdades no Brasil. Entretanto, existem poucos estudos sobre - BPC que tratam da implementação, expansão do seu al cancee avaliação de impacto na vida dos beneficiados. A pesquisa que fundamentou este artigo avaliou aspectos relativos ao impacto do BPC, uma variável rara nos estudos nacionais.

Os principais achados dessa pesquisa apontam para a necessidade de estudos futuros com a finalidade de levar adiante al guns temas levantados aqui de maneira ainda exploratória - critérios de elegibilidade, proteção social, mercado de trabalho e cuidadoras de deficientes - mas que não deixam de ter importância significativa tanto para o campo dos estudos sobre políticas sociais como o campo dos estudos sobre deficiência no Brasil. 


\section{Referências}

1. Diniz D. 0 que é deficiência? Coleção Primeiros Passos. São Paulo: Brasiliense; 2007.

2. Barnes C, Barton L, Oliver M. Disability Studies Today. Cambridge: Polity Press; 2002.

3. Oliver M, Barnes C. Disabled People and Social Policy: from exclusion to inclusion. London: Longman 1998.

4. Scully JL. Corporificação da deficiência e uma ética do cuidar. In: Diniz D, organizadora. Admirável N ova Genética: Bioética e Sociedade. Brasília: LetrasLivres/UnB; 2005.

5. Brah A. Diferença, diversidade e diferenciação. Cadernos Pagu [periódico na Internet] 2006 [acessado 2007 out 01] 26:[cerca de 48 p.]. Disponível em: http://www.scielo.br/pdf/cpa/n26/30396.pdf

6. Santos WR. Pessoas com deficiência: nossa maior minoria. Physis (Rio J.) 2008; 18(3):501-519.

7. Medeiros M, Britto T, Soares F. Programas focalizados de transferência de renda no Brasil: contribuições para 0 debate [texto para discussão $n-1.283$ ]. [acessado 2007 dez 10] Disponível em: http:// www.ipea.gov.br/default. jsp

8. Brasil. Lei no 8.742. Dispõe sobre a Lei Orgânica da Assistência Social e dá outras providências. Diário Oficial da União 1993; 8 dez.

9. Brasil. Decreto no 3.298, de 20 de dezembro de 1999. Regulamenta a Lei $n^{\circ} 7.853$, de 24 de outubro de 1989, dispõe sobre a Política Nacional para a Integração da Pessoa Portadora de Deficiência, consolida as normas de proteção, e dá outras providências. Diário O ficial da União 1999; 20 dez.

10. Brasil. Ministério do Desenvolvimento Social e Combate à fome. Benefício de Prestação Continuada. [acessado 2007 dez 10]. Disponível em: http:// www.mds.gov.br

11. Santos WR. Deficiência e BPC: o que muda na vida das pessoas atendidas? In: Anais da 60 - Congresso Anual da SBPC 2008; 2008; Campinas. p. 694.

12. Strauss A, Corbin J. Pesquisa qualitativa: técnicas e procedimentos para 0 desenvolvimento de teoria fundamentada. Porto Alegre: Artmed; 2008.
13. Squinca F. Deficiência e aids: o Judiciário e o Benefício de Prestação Continuada [dissertação]. Brasília (DF): UnB/FS; 2007.

14. Diniz D, Squinca $F$, Medeiros M. Qual deficiência? Perícia médica e assistência social no Brasil. Cad Saude Publica 2007; 23(11):2589-2596.

15. Medeiros M, Diniz D, Squinca F. Estudo do Programa Brasileiro de Transferência de Rendas para a população com deficiência e suas famílias: uma análise do Benefício de Prestação Continuada [texto para discussão n 1.184]. Braślia: IPEA; 2006.

16. Brasil. M inistério do Desenvolvimento Social e Combate à fome. Avaliação das pessoas com deficiência para acesso ao Benefício de Prestação Continuada da Assistência Social: um novo instrumento baseado na Classificação Internacional de Funcionalidade, Incapacidade e Saúde. Brasília: M DS; 2007.

17. Boschetti I. Seguridade Social e Trabalho: paradoxos na construção das Políticas de Previdência e Assistência Social no Brasil. Brasília: LetrasLivres/UnB; 2006.

18. Neri MC. Retratos da deficiência no Brasil. Rio de Janeiro: FGV; 2003.

19. Sen A. Desenvolvimento como liberdade. São Paulo: Companhia das Letras; 2000.

20. Sen A. Desigualdade reexaminada. Rio de Janeiro: Record; 2001.

21. Squinca $F$. $O$ risco genético reprodutivo na perspectiva das cuidadoras de crianças e adolescentes com anemia falciforme [monografia]. Brasília (DF): Universidade de Brasília; 2005.

Artigo apresentado em 21/02/2008

Aprovado em 29/10/2008

Versão final apresentada em 12/11/2009 